\title{
EDUCATIONAL
}

TECHNOLOGY

\section{Lessons from EdTech'86}

\section{Peter Hosie \\ for the Conference Committee}

The Australian Society for Educational Technology holds a biennial Conference to allow members and others interested in education and technology to get together, discuss issues and share experiences. The 1986 Conference, EdTech'86, was held on the campus of the University of Western Australia in December 1986. Peter Hosie summarises an evaluation of the Conference, with special reference to the next ASET Conference EdTech '88 - to be held in Canberra in September 1988.

Evaluation is an important component of educational technology, and in an effort to practice what we preach the organisers of EdTech'86 decided to gather some reactions to our recent international conference and exhibition.

Informal congratulatory remarks abounded throughout and after the event, making it tempting to conclude that a successful event had been organised. Nevertheless it was felt that a form of more anonymous feedback was necessary. A short questionnaire (anonymous for $18 \%$ of respondents) was considered more likely to elicit a considered, possibly more frank response than acts of public bravado at the bar! Indeed considering there were 84 interstate and 15 overseas guests who came to Perth we have a responsibility to eliminate weaknesses and capitalise on strengths in preparation for the 1988 conference in Canberra. Hopefully this short analysis of information supplied by a small sample $(14 \%, \mathrm{n}=39)$ of the 281 who registered for the conference will assist this task.

\section{Who attended?}

Respondents were broadly representative of conference registrants. There was a strong representation from those employed by tertiary institutions and Education Departments, including the TAFE sector. Of these, administrators or managers and their teaching and academic colleagues comprised the bulk of attendees who managed to join us in the leafy grounds of the University of Western Australia (incidentally, there was no category for educational technologist) School teachers were noticeably absent - chiefly the result of inadequate canvassing and the timing of the conference. Considering the primacy of implementing educational technology into the nation's classrooms, 
future conferences should endeavour to make provision for school teachers to attend conferences. Also active encouragement should be given to encouraging classroom practitioners to present papers and lead workshops.
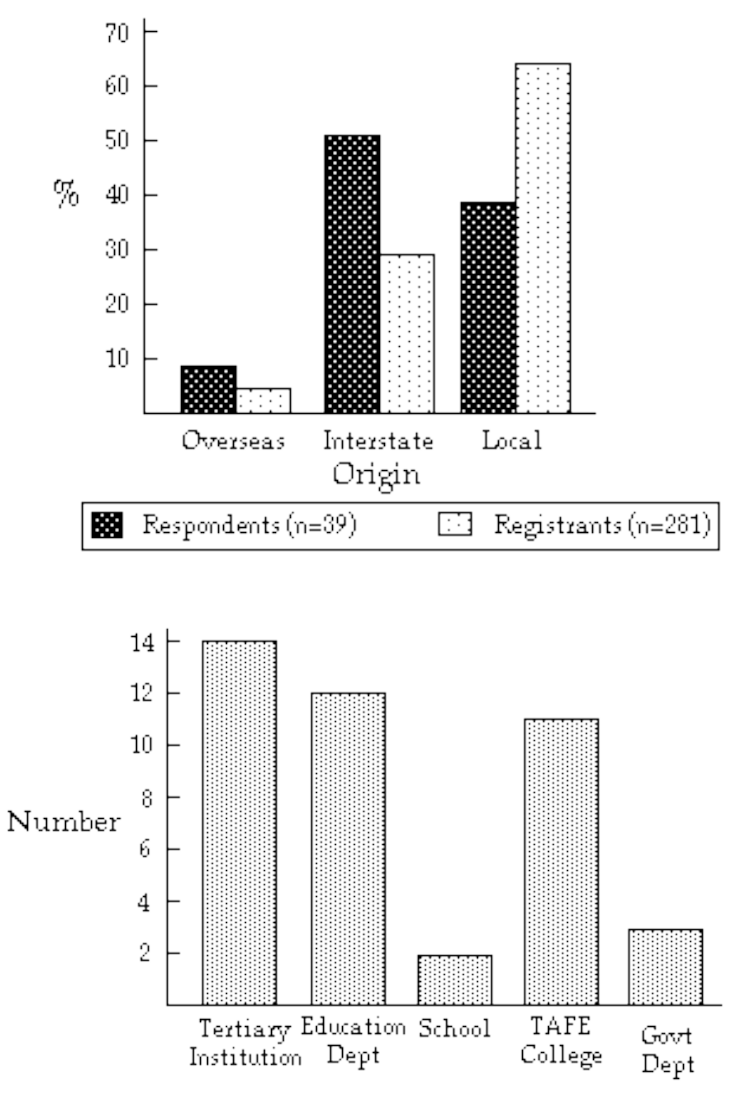

Institutional Affiliation

Overall the reaction to the conference was positive, with almost all reactions falling in the "Excellent" to "Good" categories. Plenary session speakers were rated highly. There was slightly less enthusiasm for the parallel sessions although some people indicated that the parallel sessions presenters were of variable quality. Only one person considered they were Poor, with majority considering they were Good. Considering the large number of parallel session speakers (all people who offered to present a paper or workshop were given a place in the program), it was understandable that the quality did vary at times.

Some respondents reported difficulties deciding at times between competing sessions. The organisers aimed to provide a program with "something for everyone", but it might be wiser in future to choose sessions more carefully and as much as possible avoid scheduling certain sessions in parallel. Making adequate provision within the program for colleagues to get together 
informally was also considered important. Special Interest Group sessions featured prominently in the program and respondents indicated that such sessions provided a valuable opportunity to meet with others working in similar fields and discuss issues of common interest.

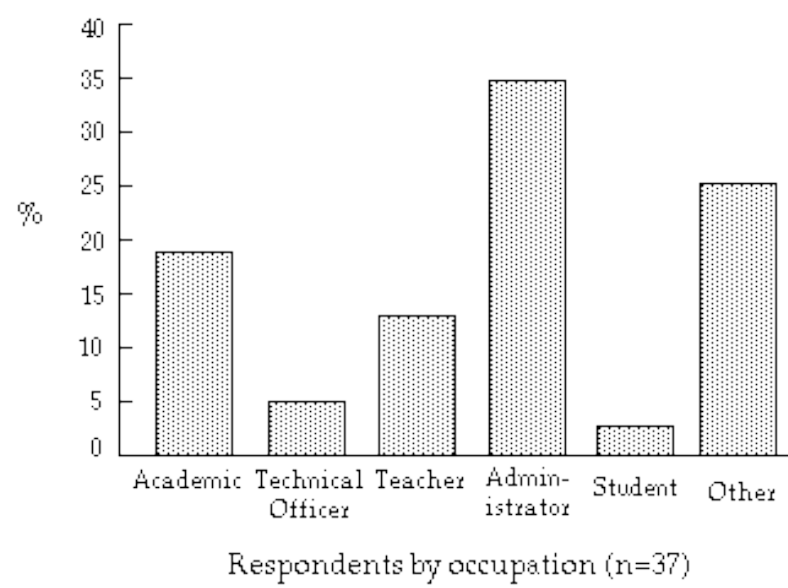

The exhibition was received favourably, but was not as highly regarded by respondents as might have been expected by informal comments from people during the Conference itself.

Overall, the conference organisation was well regarded with several supportive comments about the quality of the program material. One common comment was the desirability of having a single point of contact for registrants for accommodation and program inquiries.

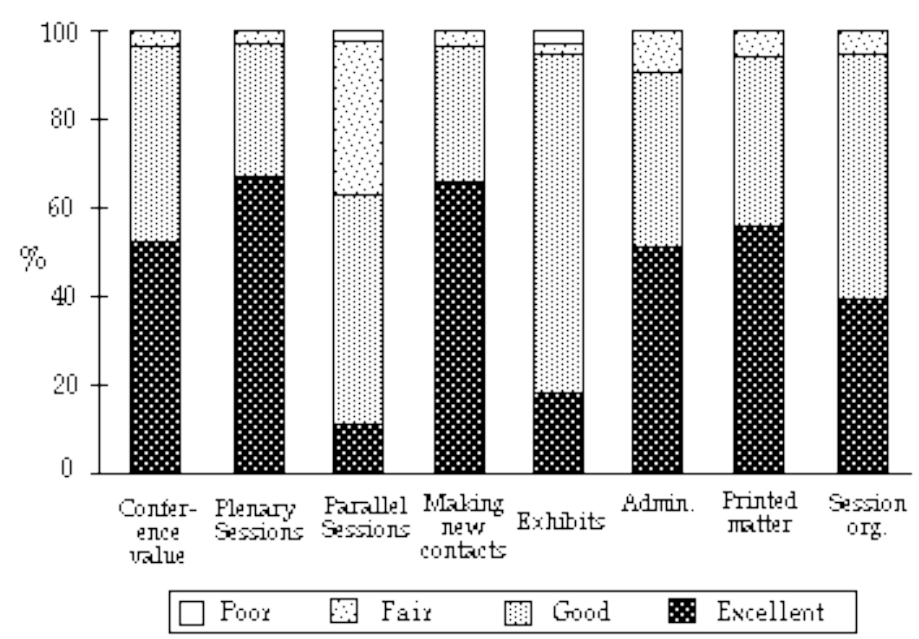


There was a variety of responses to the question asking which session was of most use to delegates. Michael Tibbet's session on The Domesday Project, a twentieth century interactive videodisc version of Domesday book, was mentioned several times A number of people indicated Michael's presentation was highly motivating and were impressed by his motto': "anything is possible". Parallel speakers Nigel Russell (Interactive Videodisc - An Aussie Barbeque Experience) and Orson Tormey and Ian Hart (Desk-Top Publishing in Education) were two sessions that received praise for presentation competence and valuable information. Of particular interest was keynote speaker Nigel Paine from the Scottish Council for Educational Technology who was able to inspire fire in the hearts of those who wish to see education reformed. He argued strongly that if educationalists fail to respond to the new technological networks being established and curriculum areas being developed then alternative means of formal and informal learning will develop.

The least valuable presentations were, as one respondent aptly remarked, the most readily forgotten. Criticisms centred on parallel session speakers who either read papers, gave disorganised presentations or left no provision for questioning.

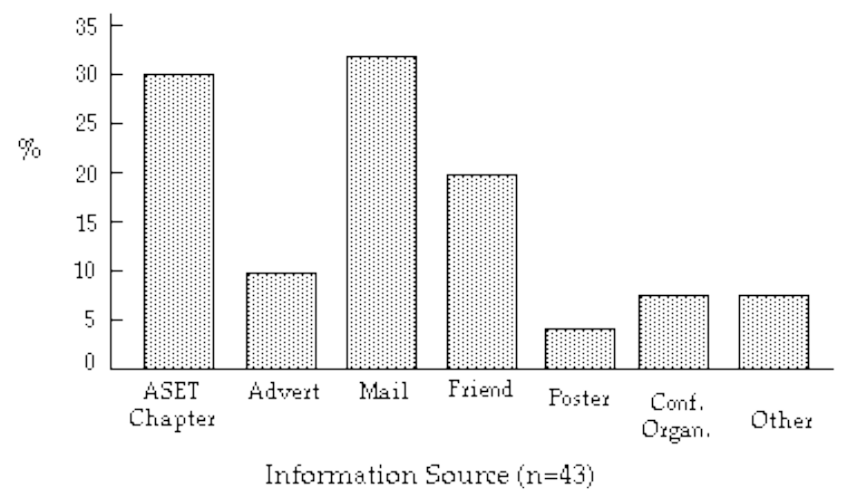

Clearly the two most successful methods of disseminating information about the conference were through the local ASET Chapter and from information mailed directly to organisations or individuals. Posters had almost no impact and were expensive to produce. While few people indicated that newspaper or journal advertisements were a source of information, not a great deal of effort was expended in this area. Perhaps future conference organisers will be able to target journals suitable for placement of advertising. (A number of international journals such as Media in Education and Development and Journal of Educational Television did insert advertisements for EdTech'86 at minimal or no charge). However, there are a number of other UK based journals which could carry notices for the next Conference, and more effort should be made to attract overseas - especially North American educational technologists.) Perhaps the most successful method is to use direct mailing. Most respondents indicated they would prefer the conference to be held in November or December. 
There was a great range of themes or topics suggested for future conferences. Educational computing featured strongly as did new technology developments. Respondents indicated a preference for reports on existing Australian projects of a practical nature, especially those which could demonstrate a good return on investment. Some argued persuasively for more exploration of how students learn before describing how they learn with technology. Interest was also expressed in educational broadcasting, low-cost materials, non-broadcast video, interactive videodisc and instructional design, most of which were covered in EdTech'86. In all there was no discernible pattern of preferences.

Extensive comments were made about the conference in general. Few complaints were evident, although some comment was made about the long food queues (a problem at most large gatherings of people). There was a consistent request for copies of papers to be available before and directly after sessions, particularly for keynote speakers. While the organisers also considered this desirable, few papers were supplied by presenters before the conference. Provision was made for people to photocopy papers at low cost during the conference. Predicting how many copies of each paper will be in demand is a difficult business.

There would seem to be a place for a one stop educational technology shop, perhaps integrated with software or hardware exhibits, which could be used to market the excellent materials produced in Australia. At the very least there should be an opportunity for all ASET awards to be viewed or demonstrated. A number of people were in favour of having ASET awards on the night of the conference dinner.

Parallel session time allocations were considered appropriate and several people commented on the relaxed yet well organised nature of the program. Chairpeople should continue to be used and there is a need to ensure that speakers keep to time allocations as well as allowing adequate opportunities for questions.

The technical assistance given was highly praised. Conference organisers were fortunate to have a surfeit of competent and highly cooperative technical staff. Given the ever increasing complexity of conferences involving technology it is essential to have an adequate supply of technicians.

While it is easy to be wise after the event a sharpening of the focus of future themes might aid keynote presentations to be better integrated.

This quote summed up much of the reaction:

Heaps of congratulations to the organisers. I heard no complaints from overseas or interstate people and from my point of view everything was efficient, well-timed and cheerfully organised. Well done!

Please cite as: Hosie, P. (1987). Lessons from EdTech'86. Australian Journal of Educational Technology, 3(1), 1-5.

http:/ / www.ascilite.org.au/ajet/ajet3/hosie.html 